\title{
LOW-CONCENTRATION SODIUM SELENITE APPLICATIONS IMPROVE OXIDATION RESISTANCE OF FILLING-STAGE RICE
}

\author{
HE, L. X. $.^{1,2 \# *}-$ ZHENG, A. X. ${ }^{1,2 \#}-$ DU, B. ${ }^{1,2 \#}-$ LUO, H. W. ${ }^{1,2}-$ LU, R. H. ${ }^{1}-$ DU, P. ${ }^{3}-$ CHEN, Y. L. ${ }^{1}-$ \\ ZHANG, T. T. ${ }^{1,2}-$ LAI, R. F. ${ }^{1,2}-$ TANG, X. R. ${ }^{1,2 *}$ \\ ${ }^{I}$ Department of Crop Science and Technology, College of Agriculture \\ South China Agricultural University, 510642 Guangzhou, PR China \\ ${ }^{2}$ Scientific Observing and Experimental Station of Crop Cultivation in South China \\ Ministry of Agriculture, 510642 Guangzhou, PR China \\ ${ }^{3}$ Key Laboratory of Key Technology for South Agricultural Machine and Equipment \\ Ministry of Education, 510642 Guangzhou, PR China \\ ${ }^{\#}$ These authors have contributed equally to this work. \\ ${ }^{*}$ Corresponding author \\ e-mail: tangxr@scau.edu.cn; phone/fax:+20-8528-0204-618 \\ (Received $16^{\text {th }}$ Aug 2018; accepted $2^{\text {nd }}$ Jan 2019)
}

\begin{abstract}
Effects of sodium selenite treatments on rice were investigated using two known cultivars Xiangyaxiangzhan and Meixiangzhan2 cultivated at two sites of Guangdong Province, China. Sodium selenite solutions at $10(\mathrm{Se} 1), 30(\mathrm{Se} 2)$ and $50(\mathrm{Se} 3) \mu \mathrm{mol} \cdot \mathrm{L}^{-1}$ were sprinkled to the rupturing-stage rice separately, with a control set with double distilled water instead. For Xiangyaxiangzhan, comparing with control, 6.91, 24.81 and $25.00 \%$ higher SOD, POD and CAT activity were recorded in Se1. For Meixiangzhan2, 2.10, 9.44 and $10.00 \%$ higher SOD, POD and CAT activity were recorded in Se1. Moreover, high-concentration sodium selenite (Se3) depressed the antioxidant enzyme activities and caused MDA over-production in Xiangyaxiangzhan. In conclusion, sodium selenite low-concentration applications could be an exogenous regulator to improve rice oxidation resistance in rice production.
\end{abstract}

Keywords: sodium selenite, rice, yield, antioxidant enzymes, malondialdehyde

\section{Introduction}

As a staple food in most Asian nations, rice contributes to $35 \%-75 \%$ of caloric intake for more than three billion people around the globe, which means rice production is an important part of the global food security system. The world population may increase to 10 billion, which intensifies the demand of rice in the next few decades (Krishnan et al., 2007). However, many uncertain factors could affect the rice yield and quality. Normally, rice is widely grown where the rainfall during the growing season is 50-3000 mm. Paddy fields are often under inundated condition for long time and produce abundant reduced toxic matter, such as ferrous ion and organic acids (XinLiu and Song, 2004), which could negatively affect rice growth. However, the concerns over the effects of global climate change and heavy metal pollution on crop growth and yield have been increased markedly (Krishnan et al., 2007). The stresses of environment pollution and climate changes would cause great loss in rice yield and quality, if the stress tolerance of rice plants cannot be strengthened. Hence, cultivation techniques should be improved in order to ensure the food security novel genetic approaches, of which exogenous regulators might be necessary in rice production. 
Selenium (Se) is an essential element to humans, animals and plants. Se deficiency is associated with poor immune function, increased risk of mortality, and cognitive decline, while Se sufficiency or supplementation has antiviral effects and reduces the risk of autoimmune thyroid disease. Se could be a cancer-protective agent (Gladyshev et al., 1999). Moreover, the physiological response to Se varies considerably among plants because some plant species growing on seleniferous soils are tolerant and could accumulate abundant Se, but most plants are Se nonaccumulators and Se-sensitive (Terry et al., 2000). It has been proved that Se helps to resist toxic elements such as arsenic, antimony, mercury and copper (Gotsis, 1982; Srivastava et al., 2009). The study of $\mathrm{Hu}$ et al. (2014) showed that Se fertilizer significantly decreases the accumulation of cadmium and lead in rice tissues. Moreover, Proteomics analysis suggests Se treatment could highly affect the biological processes of rice seedlings, such as primary metabolism, photosynthesis and redox homeostasis (Wang et al., 2012). Thus, Se might be a potential exogenous regulator that helps to ensure the food security in rice production.

As is well-known, Se not only is a component element of glutathione peroxidase and thioredoxin reductase, but also is the key component of the catalyzing active center. Se could enhance the activity of glutathione peroxidase and hence the resisting oxidation, scavenge abundant free radicals and protect membranes from the injury of lipid peroxidation (Xin et al., 2004). Suitable Se supply promotes the growth of rice seedlings, but excessive Se injures rice plants and reduces biomass, especially in the roots (Liu et al., 2004).

Hence, this study was conducted in Guangdong (a major rice-producing province in South China) with the hypothesis that exogenous sodium selenite application in the rupturing stage could enhance the rice antioxidant capacity during the filling stage.

\section{Materials and Methods}

\section{Plant materials and growing condition}

Two rice cultivars, Xiangyaxiangzhan and Meixiangzhan2 with a growth period of 111-114 days, which were planted widely in South China, were used as materials and planted at late season in both Guangzhou $\left(23^{\circ} 16^{\prime} \mathrm{N}, 113^{\circ} 23^{\prime} \mathrm{E}\right)$ and Zengcheng $\left(23^{\circ} 13^{\prime}\right.$ N, $113^{\circ} 81^{\prime}$ E), Guangdong, China. Both experimental sites enjoyed a subtropical monsoon climate with mean annual air temperatures of $22.4^{\circ} \mathrm{C}$ and mean annual precipitation of $2680.9 \mathrm{~mm}$. Before sowing, the seeds were soaked in water for $24 \mathrm{~h}$, germinated in manual climatic boxes for another $24 \mathrm{~h}$, and shade-dried, followed by sowing in polyvinyl chloride trays for nursery raising. Then the 20-day-old seedlings were transplanted to the fields at the planting distance of $30 \times 12 \mathrm{~cm}^{2}$. Rice seedlings were transplanted in July and harvested in Octorber. The experimental soil in Guangzhou was sandy loam containing $25.65 \%$ organic matter, $1.360 \%$ total N, $0.956 \%$ total $\mathrm{P}$, and $17.460 \%$ total $\mathrm{K}$, while that in Zengcheng was sandy loam with $20.12 \%$ organic matter, $1.408 \%$ total $\mathrm{N}, 1.068 \%$ total $\mathrm{P}$, and $15.767 \%$ total $\mathrm{K}$.

\section{Treatments and plant sampling}

Four treatments were as set: Overhead sprinkle with $0,10,30$ and $50 \mu \mathrm{mol} \cdot \mathrm{L}^{-1}$ sodium selenite at the rupturing stage of rice, which were marked as CK (double distilled water instead), Se1, Se2 and Se3, respectively. A special Knapsack Electric 
sprayer (3WBD-Qianfeng Agricultural machinery, Yangjiang, Guangdong, China) with $0.2-0.5 \mathrm{mPa}$ pressure and $16-18 \mathrm{~L}$ capacity fitted with a special windproof atomizing spray nozzle was used for sprinkle. The treatments were arranged in randomized complete block design (RCBD) in triplicate in each year with net plot size of $36 \mathrm{~m}^{2}$. Fresh leaves were separated and collected from the rice plants after 15 days at the heading stage, washed with double distilled water and stored at $-80^{\circ} \mathrm{C}$ for physiobiochemical analysis.

\section{Yield and yield-related traits}

At the maturity stage, the rice grains were harvested from six unit sampling areas $\left(1.75 \mathrm{~m}^{2}\right)$ in each plot and then threshed. The harvested grains were sun-dried and weighed in order to determine the grain yield. Twenty hills of rice from different locations in each plot were sampled for estimation of average effective panicle number per hill. At flowering, 30 panicles were randomly marked and then sampled from each treatment and weighed. Seed-setting rate was measured as: Panicle Weight2PanicleWeight1/Time2- Time1 (Kong et al., 2017). Then representative plants from three hills were taken to estimate the yield-related traits.

\section{Estimation of malondialdehyde (MDA) and anti-oxidant responses}

The MDA content and activities of peroxidase (POD), superoxide (SOD) and catalase (CAT) were detected according to the methods of Kong et al. (2017). After MDA reacted with thiobarbituric acid, the absorbance was read at the 532, 600 and 450 $\mathrm{nm}$. The MDA content in the reaction solution was calculated as: MDA content $(\mu \mathrm{mol} / \mathrm{L})=6.45\left(\mathrm{OD}_{532}-\mathrm{OD}_{600}\right)-0.56 \mathrm{OD}_{450}$, and finally expressed as $\mu \mathrm{mol} / \mathrm{g} \mathrm{FW}$.

POD (EC 1.11.1.7) activity was estimated after the reaction in the solution including enzyme extract $(50 \mu \mathrm{l}), 1 \mathrm{ml}$ of $0.3 \% \mathrm{H}_{2} \mathrm{O}_{2}, 0.95 \mathrm{ml}$ of $0.2 \%$ guaiacol, and $1 \mathrm{ml}$ of 50 $\mathrm{mM} \cdot 1^{-1}$ sodium phosphate buffer (SPB, $\mathrm{pH} 7.0$ ). One POD unit of enzyme activity was expressed as the absorbance increase by 0.01 (U/g FW) due to guaiacol oxidation. SOD (EC 1.15.1.1) activity was measured by using nitro blue tetrazolium (NBT). In brief, $0.05 \mathrm{ml}$ of an enzyme extract was added into the reaction mixture which contained 1.75 $\mathrm{ml}$ of SPB (pH 7.8), $0.3 \mathrm{ml}$ of $130 \mathrm{mM}$ methionine buffer, $0.3 \mathrm{ml}$ of $750 \mu \mathrm{mol} \cdot \mathrm{L}^{-1} \mathrm{NBT}$ buffer, $0.3 \mathrm{ml}$ of $100 \mu \mathrm{mol} \cdot \mathrm{L}^{-1}$ ethylene diamine tetraacetic acid (EDTA)-2Na buffer and $0.3 \mathrm{ml}$ of $20 \mu \mathrm{mol} \cdot \mathrm{L}^{-1}$ lactoflavin. After the reaction, the absorbance was recorded at $560 \mathrm{~nm}$. One unit of SOD activity was equal to the volume of the extract needed to cause 50\% inhibition of the color reaction. CAT (EC 1.11.1.6) activity was estimated by adding an aliquot of enzyme extract $(50 \mu \mathrm{l})$ to the reaction solution containing $1 \mathrm{ml}$ of $0.3 \% \mathrm{H}_{2} \mathrm{O}_{2}$ and $1.95 \mathrm{ml}$ of SPB and then the absorbance was read at $240 \mathrm{~nm}$. One CAT unit of enzyme activity was defined as the absorbance decrease by 0.01 (U/g FW).

\section{Detection of Chlorophyll contents}

The contents of total chlorophyll (total $\mathrm{Chl}$ ), chlorophyll a (Chl a) and chlorophyll b (Chl b) were detected by the methods of Anjum (2016). A ground leaf sample (about $0.1 \mathrm{~g}$ ) was placed in a $15 \mathrm{ml}$ centrifuge tube along with $95 \%$ absolute ethyl alcohol (10 $\mathrm{ml}$ ) and then kept at dark until the sample turned white. Then $\mathrm{Chl} \mathrm{a,} \mathrm{Chl} \mathrm{b} \mathrm{and} \mathrm{total} \mathrm{Chl}$ contents were estimated at 645, 652 and $663 \mathrm{~nm}$ respectively on an ultraviolet-visible spectrophotometer. 


\section{Statistical analysis}

Data were analyzed on Statistix 8.1 (Analytical Software, Tallahassee, FL, USA) while differences among means were separated by using least significant difference (LSD) test at 5\% probability level. Graphical representation was conducted via Sigma Plot 14.0 (Systat Software Inc., California, USA).

\section{Results}

\section{MDA content}

Sodium selenite applications significantly affected the MDA contents in rice leaves at the filling stage (Figure 1). For Xiangyaxiangzhan in both Guangzhou and Zengcheng, MDA contents under Se1 treatment were significantly lower compared with $\mathrm{CK}, \mathrm{Se} 2$ or $\mathrm{Se} 3$, while the MDA contents increased with the increment of sodium selenite concentration. For Meixiangzhan2, MDA contents in Guangzhou were not remarkably different among $\mathrm{CK}, \mathrm{Se} 1$ and $\mathrm{Se} 3$, but significantly decreased after the $\mathrm{Se} 2$ treatment. In Zengcheng, however, both $\mathrm{Se} 1$ and $\mathrm{Se} 2$ treatments lowered the MDA contents compared with $\mathrm{CK}$ and the trend was $\mathrm{Se} 2<\mathrm{Se} 1<\mathrm{CK}<\mathrm{Se} 3$.
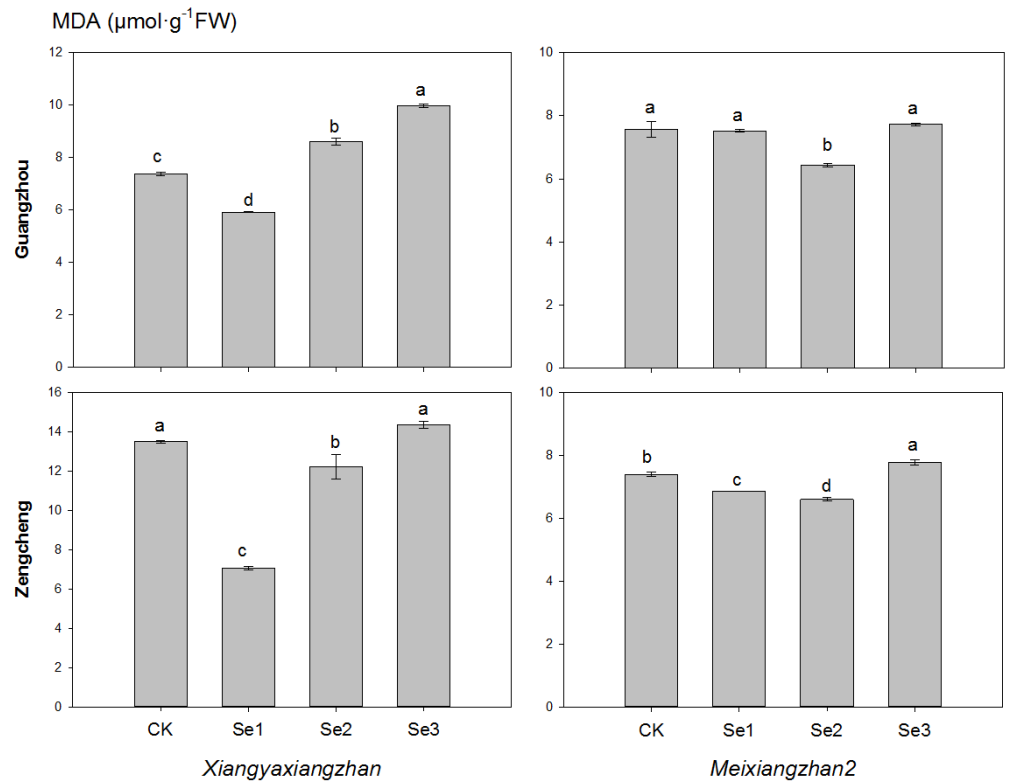

Figure 1. Effects of sodium selenite application on MDA contents. Means sharing a common letter don't differ significantly at $(P \leq 0.05)$ according to least significant difference $(L S D)$ test.

The same as below

\section{Anti-oxidant responses}

Sodium selenite applications into Xiangyaxiangzhan regulated the anti-oxidant system in terms of POD, SOD and CAT activities and soluble protein contents (Figure 2). For example, POD activity was maximized in Se1 while did not significantly differ among CK, Se2 and Se3. For Meixiangzhan2, POD activity was the highest in Se2 and 
changed in the trend of $\mathrm{CK}<\mathrm{Se} 3<\mathrm{Se} 1<\mathrm{Se} 2$. SOD activity was significantly higher in $\mathrm{Se} 1$ treatment and was lowest in Se3 for Xiangyaxiangzhan. For Meixiangzhan2, SOD activity did not remarkably differ between CK and sodium selenite treatments in Guangzhou, but in Zengcheng, SOD activity under Se2 treatment was significantly higher than in CK, Se1 and Se3, which were 278.32, 229.13, 235.68 and $244.83 \mathrm{U} \mathrm{g}^{-}$ ${ }^{1} \mathrm{~min}^{-1} \mathrm{FW}$, respectively. Compared with $\mathrm{CK}$, CAT activities under Se1 treatment in Guangzhou and Zengcheng were 1.24 and 1.08 fold higher for Xiangyaxiangzhan. For Meixiangzhan2, the CAT activity was improved by both $\mathrm{Se} 1$ and $\mathrm{Se} 2$, but was maximized in Se2 treatment in two locations. The effects of sodium selenite on soluble protein accumulation differed among treatments and between cultivars. For Xiangyaxiangzhan, the trend of soluble protein contents was $\mathrm{Se} 3<\mathrm{CK}<\mathrm{Se} 2<\mathrm{Se} 1$ in Guangzhou, but did not significantly differ among treatments in Zengcheng. For Meixiangzhan2, the highest protein concentration in Guangzhou was recorded in Se1; the contents in Se1 and Se2 were significantly higher than CK and Se3 in Zengcheng.
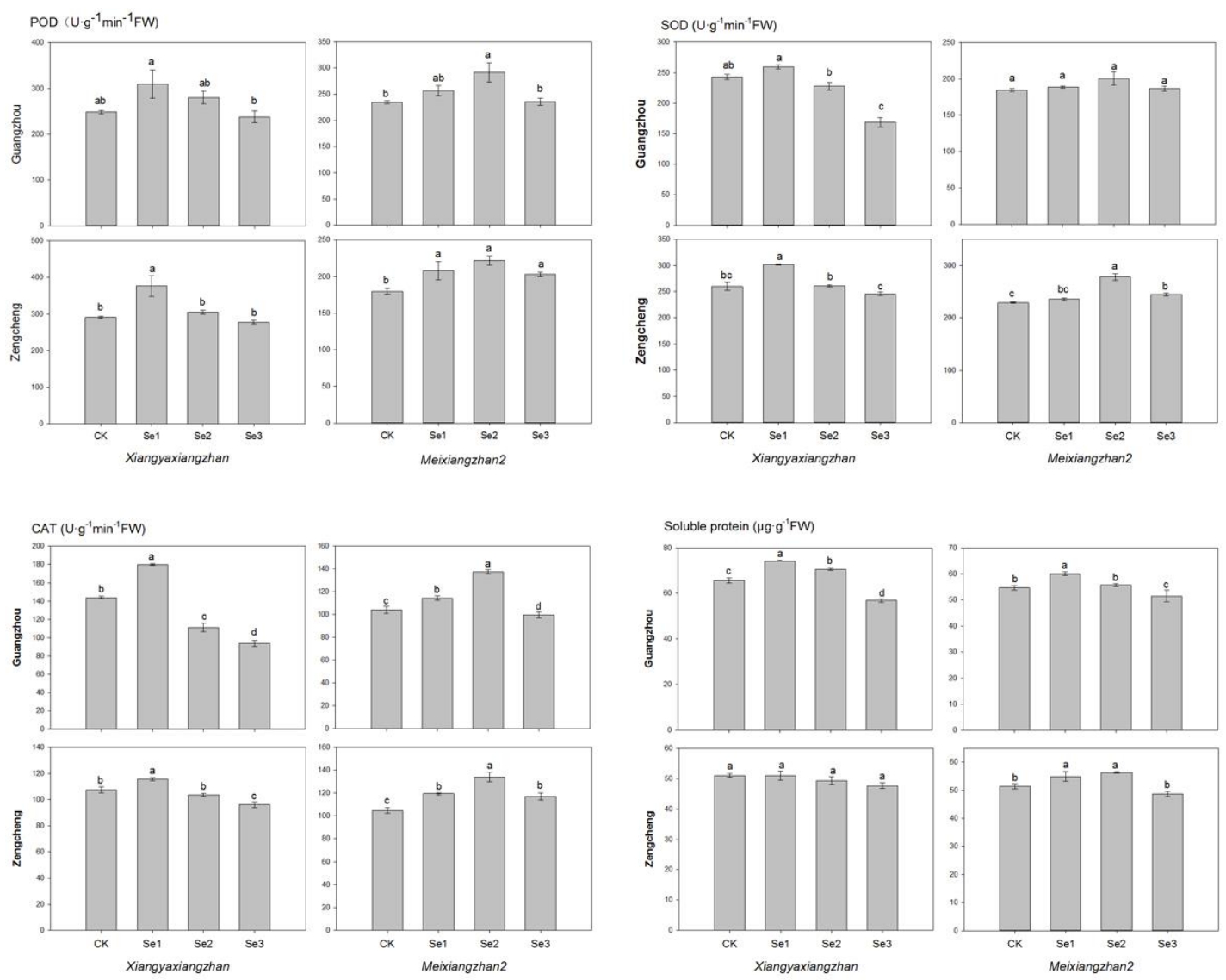

Figure 2. Effects of sodium selenite application on anti-oxidant responses

\section{Chlorophyll}

Chlorophyll contents were significantly affected by sodium selenite applications (Figure 3). For Xiangyaxiangzhan, the total $\mathrm{Chl}$ content maximized in $\mathrm{Se} 1$ and minimized in Se3 for both Guangzhou and Zengcheng, and a similar trend was found in $\mathrm{Chl}$ a contents. For Meixiangzhan2 in Guangzhou, total Chl contents under Se1, Se2 and $\mathrm{Se} 3$ were $1.10,1.18$ and 1.06 fold higher than $\mathrm{CK}$, respectively, and the trends of 
both $\mathrm{Chl}$ a and $\mathrm{Chl} b$ were recorded as: $\mathrm{CK}<\mathrm{Se} 1<\mathrm{Se} 3<\mathrm{Se} 2$. In Zengcheng, however, total $\mathrm{Chl}$ contents were not remarkably different between Se1 and Se2, but were both higher than $\mathrm{CK}$ and $\mathrm{Se} 3$, and similar trends were also found in both $\mathrm{Chl}$ a and $\mathrm{Chl} \mathrm{b}$.
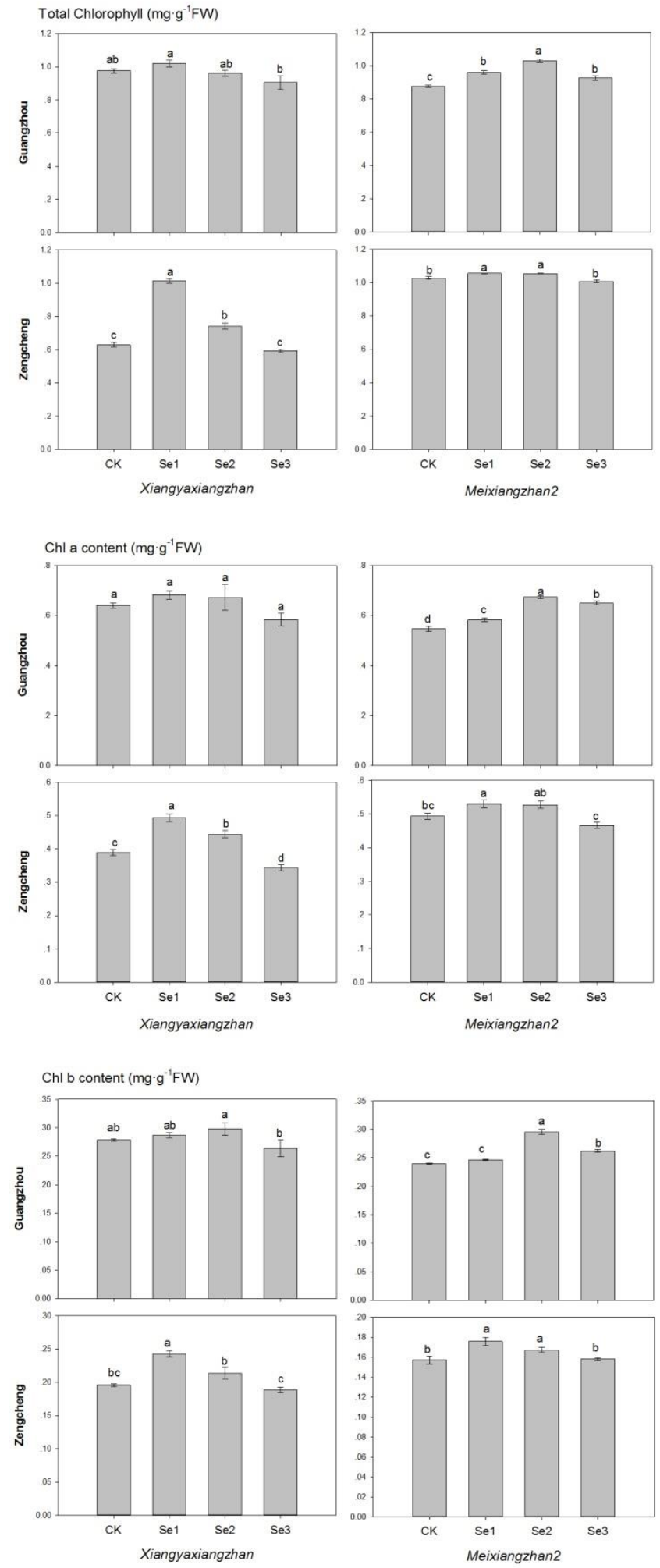

Figure 3. Effects of sodium selenite application on chlorophyll contents 


\section{Yield and yield-related traits}

No significant difference among CK, Se1, Se2 and Se3 was found in panicle number per $\mathrm{m}^{2}$ or grain number per panicle irrespective of locations or cultivars (Table 1). For Xiangyaxiangzhan, however, seed- setting rate of Se2 was higher than CK, Se1 and Se3 in Zengcheng, which were $78.85 \%, 70.81 \%, 66.53 \%$ and $71.43 \%$, respectively. In Guangzhou, 1000-grain weights of Se1 and Se2 remained higher than CK and Se3. Furthermore, Se1 significantly improved grain yield compared with CK. For Meixiangzhan2, the sodium selenite treatments had no remarkable effect on seed-setting rate, grain weight or yield.

\section{Discussion}

As one of the important life elements, Se has many similar chemical properties as sulfur (S). The most important biofunction of $\mathrm{Se}$ in animals and humans is as a component of the glutathione peroxidase system (GSH-PX), which is involved in the REDOX reaction in the body, scavenging free radicals, and reducing the body peroxidation damage caused by biofilms (Qiang et al., 2011). Se could significantly enhance the antioxidant capacity of higher plants, such as wheat, corn, soybean and rape, and maintains the normal growth of plants (Wang et al., 1996; Nawaz et al., 2014). The mechanism is that Se can significantly improve the transcriptional levels of SOD and guaiacol peroxidase in plants, thus activating the antioxidant protection ability. The present study proves that sodium selenite treatments improved the activities of antioxidant enzymes, including POD, SOD and CAT. Furthermore, the sodium selenite applications also reduced oxidative damage by decreasing lipid per-oxidation (MDA concentration), while inducing dynamics in soluble proteins. Normally, the MDA production might be related to oxidation of polyunsaturated fatty acids (e.g., linoleic and linolenic acid) that play an important role in the arrangement of photosystem reaction centers. MDA could even react with free amino acids and cause ethylene overproduction in cellular membranes (Rakwal et al., 2003). Thus, MDA content could be an important indicator of oxidative stress. We observed the treatments $\mathrm{Se} 1$ and $\mathrm{Se} 2$ reduced MDA concentration and enhanced the activities of POD, SOD and CAT. This finding indicates that low-rate sodium selenite applications at the rupturing stage could improve the antioxidant performance and strength of filling-stage rice under external environment stress. This study also agreed with (Ríos et al., 2009) that low-rate selenite application could enhance the activities of $\mathrm{H}_{2} \mathrm{O}_{2}$-detoxifying enzymes, especially glutathione (GSH), POD and SOD. Moreover, selenite treatment could regulate the accumulation of soluble proteins that help in maintaining cellular structures and functions when the antioxidant system quenches reactive oxygen species.

In our study, sodium selenite applications significantly affected the chlorophyll content, and the total $\mathrm{Chl}$ contents first increased and then decreased with the increase of sodium selenite concentration. This finding agrees with (Wu et al., 2000) that the electron transfer of chloroplast is accelerated at low Se concentration.

Interestingly, the sensitivity to sodium selenite was quiet different between Xiangyaxiangzhan and Meixiangzhan2. As reported, different genotype cultivars responded differently to selenium fertilizers and differed in terms of selenium uptake and distribution. For Xiangyaxiangzhan, low concentration selenite applications such as Se1 significantly improved the activities of antioxidant enzymes, up-regulated the chlorophyll contents and increased the grain yields. 
Table 1. Effects of sodium selenite application on yield and yield-related traits

\begin{tabular}{|c|c|c|c|c|c|c|c|}
\hline Location & Cultivar & Treatment & $\begin{array}{l}\text { Panicle number } \\
\text { per } \mathbf{~ m}^{2}\end{array}$ & $\begin{array}{c}\text { Grains number } \\
\text { per panicle }\end{array}$ & $\begin{array}{c}\text { Seed-setting rate } \\
(\%)\end{array}$ & $\begin{array}{l}\text { 1000-grain weight } \\
\text { (g) }\end{array}$ & Yield $\left(\mathrm{t} \mathrm{hm}^{-2}\right)$ \\
\hline \multirow[t]{8}{*}{ Guangzhou } & \multirow[t]{4}{*}{ Xiangyaxiangzhan } & $\mathrm{CK}$ & $271.33 \pm 13.49 \mathrm{a}$ & $105.51 \pm 11.56 \mathrm{a}$ & $84.49 \pm 1.73 a$ & $18.26 \pm 0.36 \mathrm{~b}$ & $4.90 \pm 0.21 \mathrm{~b}$ \\
\hline & & Se1 & $253.02 \pm 16.33 \mathrm{a}$ & $87.47 \pm 11.05 \mathrm{a}$ & $86.45 \pm 2.57 \mathrm{a}$ & $19.49 \pm 0.06 \mathrm{a}$ & $6.65 \pm 0.19 \mathrm{a}$ \\
\hline & & $\mathrm{Se} 2$ & $246.85 \pm 33.99 a$ & $111.59 \pm 8.15 \mathrm{a}$ & $85.33 \pm 0.24 \mathrm{a}$ & $19.78 \pm 0.13 \mathrm{a}$ & $5.59 \pm 0.43 \mathrm{ab}$ \\
\hline & & $\mathrm{Se} 3$ & $286.17 \pm 29.17 \mathrm{a}$ & $93.63 \pm 1.13 \mathrm{a}$ & $86.58 \pm 1.57 \mathrm{a}$ & $18.48 \pm 0.23 b$ & $5.64 \pm 0.66 \mathrm{ab}$ \\
\hline & \multirow[t]{4}{*}{ Meixiangzhan2 } & CK & $227.40 \pm 28.23 \mathrm{a}$ & $178.37 \pm 1.04 \mathrm{a}$ & $79.26 \pm 1.95 \mathrm{a}$ & $18.84 \pm 0.21 \mathrm{a}$ & $5.33 \pm 0.72 \mathrm{a}$ \\
\hline & & Se1 & $219.66 \pm 14.76 a$ & $176.69 \pm 3.67 \mathrm{a}$ & $80.52 \pm 0.35 \mathrm{a}$ & $18.91 \pm 0.15 \mathrm{a}$ & $5.18 \pm 0.29 \mathrm{a}$ \\
\hline & & $\mathrm{Se} 2$ & $250.6 \pm 9.66 \mathrm{a}$ & $176.68 \pm 12.19 \mathrm{a}$ & $81.75 \pm 2.59 \mathrm{a}$ & $18.93 \pm 0.18 \mathrm{a}$ & $7.51 \pm 0.11 \mathrm{a}$ \\
\hline & & $\mathrm{Se} 3$ & $202.64 \pm 13.75 \mathrm{a}$ & $175.59 \pm 13.42 \mathrm{a}$ & $78.58 \pm 4.19 \mathrm{a}$ & $19.07 \pm 0.11 \mathrm{a}$ & $5.64 \pm 1.06 \mathrm{a}$ \\
\hline \multirow[t]{8}{*}{ Zengcheng } & \multirow[t]{4}{*}{ Xiangyaxiangzhan } & $\mathrm{CK}$ & $292.1 \pm 11.45 \mathrm{a}$ & $110.23 \pm 9.02 \mathrm{a}$ & $70.81 \pm 3.36 \mathrm{ab}$ & $20.27 \pm 0.35 \mathrm{a}$ & $4.23 \pm 0.61 \mathrm{a}$ \\
\hline & & Se1 & $292.1 \pm 33.11 \mathrm{a}$ & $104.62 \pm 2.95 \mathrm{a}$ & $66.53 \pm 0.27 b$ & $20.55 \pm 0.12 \mathrm{a}$ & $4.95 \pm 0.28 \mathrm{a}$ \\
\hline & & $\mathrm{Se} 2$ & $283.87 \pm 25.69 a$ & $117.19 \pm 7.37 \mathrm{a}$ & $78.85 \pm 4.84 \mathrm{a}$ & $20.36 \pm 0.11 \mathrm{a}$ & $4.88 \pm 0.53 \mathrm{a}$ \\
\hline & & $\mathrm{Se} 3$ & $306.5 \pm 20.88 \mathrm{a}$ & $106.12 \pm 6.34 \mathrm{a}$ & $71.43 \pm 3.43 \mathrm{ab}$ & $20.67 \pm 0.13 \mathrm{a}$ & $3.72 \pm 0.22 \mathrm{a}$ \\
\hline & \multirow[t]{4}{*}{ Meixiangzhan2 } & $\mathrm{CK}$ & $266.07 \pm 32.19 \mathrm{a}$ & $138.56 \pm 2.25 \mathrm{a}$ & $85.35 \pm 0.24 \mathrm{a}$ & $18.07 \pm 0.39 \mathrm{a}$ & $3.65 \pm 0.15 \mathrm{a}$ \\
\hline & & Se1 & $262.2 \pm 14.11 \mathrm{a}$ & $116.14 \pm 3.17 \mathrm{a}$ & $85.13 \pm 0.40 \mathrm{a}$ & $18.18 \pm 0.14 \mathrm{a}$ & $3.54 \pm 0.26 \mathrm{a}$ \\
\hline & & $\mathrm{Se} 2$ & $230.49 \pm 12.67 \mathrm{a}$ & $120.63 \pm 7.73 a$ & $81.51 \pm 3.76 \mathrm{a}$ & $18.41 \pm 0.07 \mathrm{a}$ & $3.85 \pm 0.20 \mathrm{a}$ \\
\hline & & $\mathrm{Se} 3$ & $259.11 \pm 14.94 a$ & $124.54 \pm 6.62 \mathrm{a}$ & $78.36 \pm 2.28 \mathrm{a}$ & $18.00 \pm 0.02 \mathrm{a}$ & $3.47 \pm 0.14 \mathrm{a}$ \\
\hline
\end{tabular}


However, high-concentration selenite application such as Se3 remarkably restricted the antioxidant system while inducing the over-production of MDA. For Meixiangzhan2, the best concentration of sodium selenite seemed to be $\mathrm{Se} 2$ with regard to the lowest MDA content and highest activities of POD, SOD and CAT, while antioxidant responses or chlorophyll contents were not significantly differet among CK, $\mathrm{Se} 1$ and Se2. The result of our study indicated different rice cultivars had different sensibility to exogenous selenite and thus more study should be done in rice sensibility for Se.

\section{Conclusions}

Sodium selenite applications at low concentration could enhance the antioxidant system in term of POD, SOD and CAT, lower the MDA production and increase the chlorophyll contents. For Meixiangzhan 2, we considered that $30 \mu \mathrm{mol} \cdot \mathrm{L}^{-1}$ was the most suitable concentration for application. For Xiangyaxiangzhan, we considered that 10 $\mu \mathrm{mol} \cdot \mathrm{L}^{-1}$ was the most suitable concentration for application. In the future, sodium selenite application could be used in the rice production to improve the rice oxidation resistance and prevent the yield loss caused by environmental stress.

Acknowledgements. This study was supported by National Natural Science Foundation of China (31271646), Student's Platform for Innovation and Entrepreneurship Training Program (201810564029), National Key R\&D Program of China(2016YFD0700301), the World Bank Loan Agricultural Pollution Control Project in Guangdong (0724-1510A08N3684) and the Technology System of Modern Agricultural Industry in Guangdong (2017LM1098). The authors declare no conflicts of interest.

\section{REFERENCES}

[1] Anjum, S. A. (2016): Chromium toxicity induced alterations in growth, photosynthesis, gas exchange attributes and yield formation in maize. - Pakistan Journal of Agricultural Sciences 53: 751-757.

[2] El-Shintinawy, F. (2000): Structural and Functional Damage Caused by Boron Deficiency in Sunflower Leaves. - Photosynthetica 36: 565-573.

[3] Gladyshev, V. N., Martín-Romero, F. J., Xu, X. M., Kumaraswamy, E., Carlson, B. A., Hatfield, D. L., Lee, B. J. (1999): Molecular biology of selenium and its role in cancer, AIDS and other human diseases. - Recent Research Developments in Biochemistry.

[4] Gong, R., Ai, C., Zhang, B., Cheng, X. (2018): Effect of selenite on organic selenium speciation and selenium bioaccessibility in rice grains of two Se-enriched rice cultivars. Food Chemistry 264: 443-448.

[5] Gotsis, O. (1982): Combined effects of selenium/mercury and selenium/copper on the cell population of the alga Dunaliella minuta. - Marine Biology 71: 217-222.

[6] Hu, Y., Norton, G. J., Duan, G., Huang, Y., Liu, Y. (2014): Effect of selenium fertilization on the accumulation of cadmium and lead in rice plants. - Plant \& Soil 384: 131-140.

[7] Kong, L., Ashraf, U., Cheng, S., Rao, G., Mo, Z., Tian, H., Pan, S., Tang, X. (2017): Short-term water management at early filling stage improves early-season rice performance under high temperature stress in South China. - European Journal of Agronomy 90: 117-126.

[8] Liu, Q., Wang, D. J., Jiang, X. J., Cao, Z. H. (2004): Effects of the Interactions Between Selenium and Phosphorus on the Growth and Selenium Accumulation in Rice (Oryza Sativa). - Environmental Geochemistry \& Health 26: 325-330. 
[9] Nawaz, F., Ashraf, M. Y., Ahmad, R., Waraich, E. A., Shabbir, R. N. (2014): Selenium (Se) Regulates Seedling Growth in Wheat under Drought Stress. - Advances in Chemistry (2014-7-22): 670-675.

[10] Qiang, X., Shu, Y., Hai-Lei, A. Z. (2011): Effects of Exogenous Nitric Oxide Donor SNP on Lipid Peroxidation Caused by Selenium in Rice Seedlings. - Acta Agronomica Sinica 37: 177-181.

[11] Rakwal, R., Agrawal, G. K., Kubo, A., Yonekura, M., Tamogami, S., Saji, H., Iwahashi, H. (2003): Defense/stress responses elicited in rice seedlings exposed to the gaseous air pollutant sulfur dioxide. - Environmental \& Experimental Botany 49: 223-235.

[12] Ríos, J. J., Blasco, B., Cervilla, L. M., Rosales, M. A., Sanchezrodriguez, E., Romero, L., Ruiz, J. M. (2009): Production and detoxification of $\mathrm{H} 2 \mathrm{O} 2$ in lettuce plants exposed to selenium. - Annals of Applied Biology 154: 107-116.

[13] Sairam, R. K., Srivastava, G. C., Saxena, D. C. (2000): Increased Antioxidant Activity under Elevated Temperatures: A Mechanism of Heat Stress Tolerance in Wheat Genotypes. - Biologia Plantarum 43: 245-251.

[14] Srivastava, M., Ma, L. Q., Rathinasabapathi, B., Srivastava, P. (2009): Effects of selenium on arsenic uptake in arsenic hyperaccumulator Pteris vittata L. - Bioresource Technology 100:1115.

[15] Terry, N., de Souza, M. P., Am, T. A. Z. (2000): Selenium in higher plants. - Annual Review of Plant Physiology \& Plant Molecular Biology 51: 401-432.

[16] Wang, Y. D., Wang, X., Wong, Y. S. (2012): Proteomics analysis reveals multiple regulatory mechanisms in response to selenium in rice. - Journal of Proteomics 75: 18491866.

[17] Wang, Z., Xie, S., Peng, A. (1996): Distribution of Se in soybean samples with different Se concentration. - Journal of Agricultural \& Food Chemistry 44: 2754-2759.

[18] Wu, Y. Y., Lu, X. Y., Peng, Z. K., Luo, Z. M. (2000): Effect of Se on physiological and biochemical characters of paddy rice. - Scientia Agricultura Sinica 33(1): 100-103. 